\title{
Difference of Disability Between Electrophysiologic Subgroups of Essential Tremor*
}

\author{
M. Cenk Akbostanci, Sedat Ulkatan, Aytaç Yigit, Nursel Aydin, Nermin Mutluer
}

\begin{abstract}
Objective: The aim of the study was to test the validity of the controversial subdivision of essential tremor (ET) patients into electrophysiological subgroups. Methods: We evaluated a hundred patients with ET using surface electromyographic (EMG) recordings of antagonist forearm muscles and distinguished three groups: the first group showed synchronous activity of antagonistic muscles, the second showed alternating activity of antagonist muscles; and the third group consisted of patients whose EMG recordings were not compatible with the other two groups. We compared patients with synchronous and alternating activity in terms of sex, age at onset, duration of illness, family history of tremor, symmetry and frequency of tremor, and the scores of a disability scale. Results: The only significant difference between the patients with synchronous and alternating activity was that the patients with synchronous activity were more disabled. Conclusion: This result adds to the evidence for distinct electrophysiological subgroups of ET with distinct clinical properties.
\end{abstract}

RÉSUMÉ: Différences dans le degré d'invalidité entre des sous-groupes électrophysiologiques de patients présentant un tremblement essentiel. But: Le but de cette étude était d'évaluer la validité d'une subdivision controversée des patients présentant un tremblement essentiel (TE) en sous-groupes électrophysiologiques. Méthodes: Nous avons évalué cent patients présentant un TE au moyen d'enregistrements électromyographiques (ÉMG) de surface des muscles antagonistes de l'avant-bras et nous les avons divisés en trois groupes. Le premier groupe avait une activité synchrone des muscles antagonistes alors que le second avait une activité alternante des muscles antagonistes. Le troisième groupe était composé de patients dont l'enregistrement ÉMG n'était pas compatible avec ceux des deux autres groupes. Nous avons comparé les patients présentant une activité synchrone à ceux qui présentaient une activité alternante quant au sexe, à l'âge de début, à la durée de la maladie, à l'histoire familiale de tremblement, à la symétrie et à la fréquence du tremblement ainsi qu'au score à l'échelle d'invalidité. Résultats: La seule différence significative entre les patients présentant une activité synchrone et une activité alternante était que les patients présentant une activité synchrone avaient un degré d'invalidité supérieur à ceux qui présentaient une activité alternante. Conclusion: Ces observations sont en faveur de l'existence de sous-groupes électrophysiologiques distincts, avec des caractéristiques cliniques distinctes, chez les patients atteints de TE.

Can. J. Neurol. Sci. 2000; 27: 60-64

Essential tremor (ET) is a common neurological disorder with slow progression over years, characterized by tremor under postural and action conditions without additional severe neurological findings and complaints. ${ }^{1}$ In the last two decades there have been attempts to classify ET on the basis of agonistantagonist muscle interaction and other electrophysiological data with the hope of identifying subgroups with good responses to specific drugs. ${ }^{2}$ Several authors have reported findings suggesting that ET could be categorized into two types: one with synchronous, and the other with alternating activity of antagonist muscles. ${ }^{1,2,3,4}$ This classification of ET has been criticized and it is now generally accepted that such classification is not yet possible, ${ }^{5,6}$ but the controversy still goes on. ${ }^{2}$

The aim of this study was to further investigate whether ET can be categorized into subtypes with synchronous and alternating contractions of antagonist muscles on the basis of clinical variables.

\section{Materials AND METHODS}

A hundred consecutive consenting ET patients from the movement disorders clinic, whose duration of tremor was at least three years, were included in the study. We used the diagnostic criteria for definite ET proposed by the Tremor Research Investigation Group (TRIG) ${ }^{7}$ as follows: 1) Presence of postural tremor in the arms that worsens with action, in the absence of any condition or drug known to cause enhanced physiologic tremor,

\footnotetext{
* Presented at the 8th Meeting and 10th Anniversary of the European Neurological Society, June 6-10, 1998, Nice, France.

From the Department of Neurology, Faculty of Medicine, Ankara University, Ankara, Turkey.

RECEIVED MARCH 31, 1999. ACCEPTED IN FINAL FORM SEPTEMBER 13, 1999. Reprint requests to: M. Cenk Akbostanci, Ankara Üniversitesi, Tip Fakültesi, Ibni Sina Hastanesi, 6. Kat, 06100, Samanpazari, Ankara, Turkey.
} 


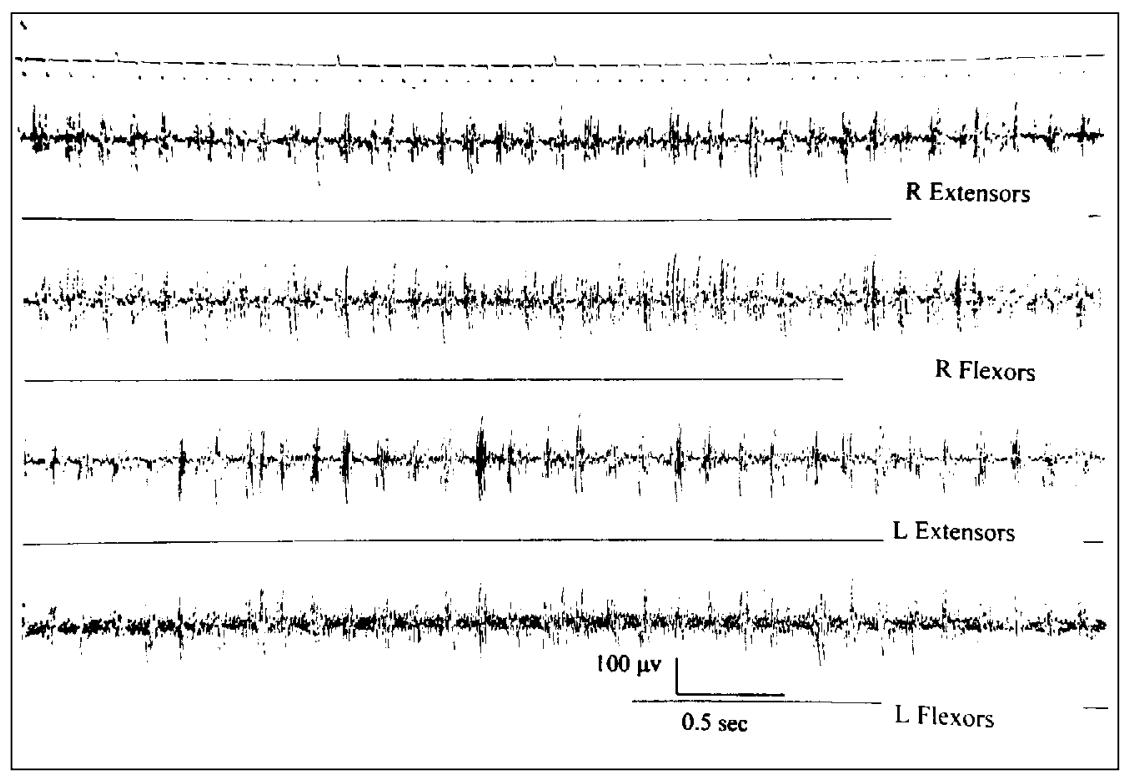

Figure 1: Synchronous activity of antagonist muscles of forearm. R: Right, L: Left Note the simultaneous contraction of flexors and extensors

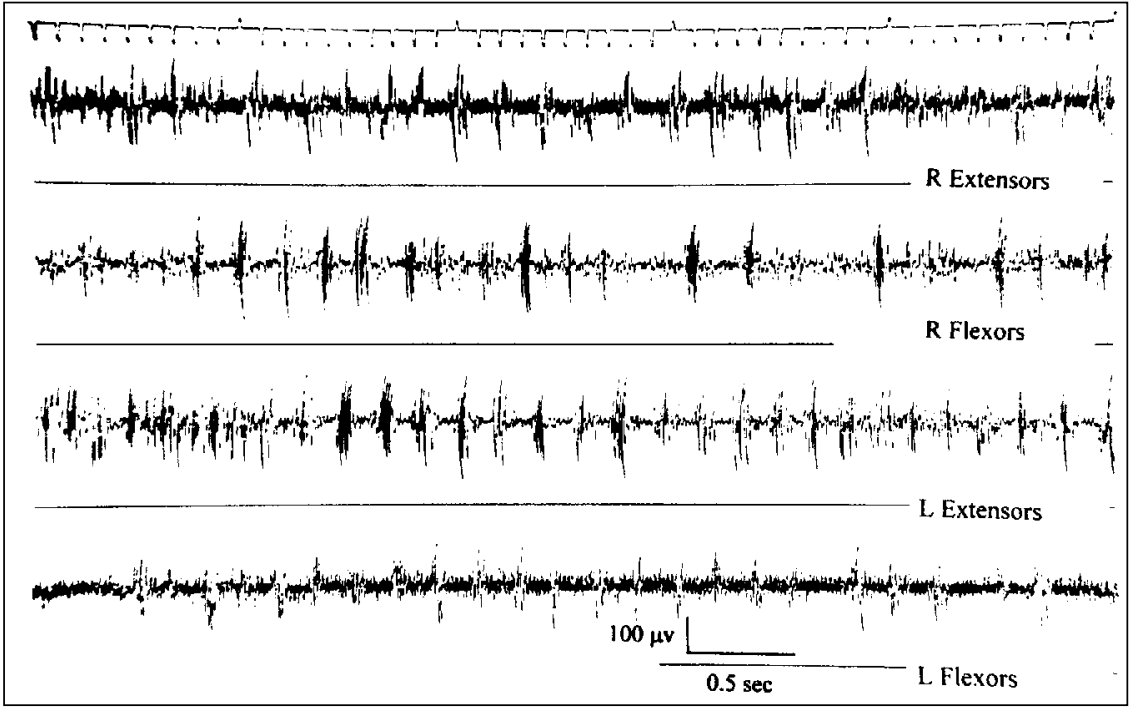

Figure 2: Alternating activity of antagonist muscles of forearm. R: Right, L: Left Flexor and extensor muscles contract one after another

in the absence of cerebellar symptoms and signs, and in the absence of Parkinson's disease, dystonia, hyperthyroidism, chronic alcoholism, peripheral neuropathy, and an anxiety state, or 2) Postural tremor of the arms without action tremor, plus head (neck) tremor, in the absence of cerebellar symptoms and signs, and in the absence of Parkinson's disease, and dystonia.

The EMG recordings were made with a San-ei EEG 1A96 electroencephalograph, using 1-cm diameter $\mathrm{Ag}-\mathrm{AgCl}$ surface electrodes from the extensor and flexor surfaces of the forearm in regions where optimum traces were obtained. The region where optimum traces was obtained frequently occurred on the extensor surface, to the distal end of the proximal one third of the distance between lateral epicondyle and radial styloid process (while the forearm was in pronation); and on the flexor surface, to one or two centimeters lateral aspect of the point on the distal end of the proximal one third of the distance between medial epicondyle and ulnar styloid process. The reference electrode was placed four centimetres distal to the active one. Crosstalk between extensor and flexor muscle groups was avoided by having the patient extend her/his wrist voluntarily and observing the continuous EMG activity from the extensor surface, provided that the recording from the flexor surface was silent. The opposite manoeuvre and the observations were done for wrist flexion. The myoelectric signals were band-pass filtered (53 to $3000 \mathrm{~Hz}$ ). 
During the recording procedure the patients were seated with their arms outstretched horizontally in pronation. The recordings were made from both hands simultaneously. The recording sessions consisted of three periods each lasting ten minutes separated by ten-minute intervals without recording. Three groups were distinguished in terms of the phasic relationships of antagonist muscles: the first group showed only synchronous activity, the second showed only alternating activity, and the third consisted of patients without a uniform activity pattern in both arms throughout the recording session. We evaluated the patients with only synchronous or only alternating activity during all three recording periods (Figures 1 and 2). We did not include the third group in the analysis for reasons explained below.

Tremor frequency was calculated as the average frequency of tremor-related EMG bursts on three epochs of one-minute duration.

Family history of tremor was accepted to be present when there was at least one first degree relative with symptoms suggesting ET.

Each patient completed a self-questionnaire to document the extent of his or her tremor-induced disability. The questionnaire consisted of an inventory of 25 activities of daily living each scaled from 0 (able to do the activity without difficulty) to 4 (cannot do the activity by yourself). The version of the scale adapted for patients with tremor by Bain et $\mathrm{al}^{8}$ was used. Patients always filled in the questionnaire form with the help of a study physician who was blind to the neurophysiological results to avoid the inappropriateness of the fact that the rating scale lacks Turkish standardization.

Data were analyzed to disclose any association between the two groups of patients having only synchronous or only alternating activity with respect to gender, family history of tremor, age of onset, disease duration, symmetry of tremor, the impact of tremor to activities of daily living, and tremor frequency.

Table 1: Clinical and neurophysiological characteristics of patients with synchronous and alternating activity of antagonist muscles.

\begin{tabular}{lccc}
\hline & Synchronous & Alternating & Total \\
$\mathbf{n}$ & 25 & 23 & 48 \\
Gender (male/female) & $14 / 11$ & $13 / 10$ & $27 / 21$ \\
Mean Age & $54.4 \pm 16$ & $51.7 \pm 18.2$ & $53 \pm 17$ \\
Mean Age of Onset & $46.8 \pm 16$ & $45.6 \pm 19.7$ & $46.1 \pm 18$ \\
Mean Disease Duration & $7.6 \pm 9$ & $6.1 \pm 4.6$ & $6.9 \pm 6.8$ \\
Family History of Tremor & & & \\
$\quad$ Present/Absent & $12 / 13$ & $12 / 11$ & $24 / 24$ \\
Tremor Symmetric/Asymmetric & $15 / 10$ & $13 / 10$ & $28 / 20$ \\
ADL* Rating Scale Score** & $49 \pm 16$ & $40 \pm 10$ & $45 \pm 14$ \\
Mean Frequency (Hz) & $7.4 \pm 1.3$ & $7.7 \pm 1.5$ & $7.5 \pm 1.4$ \\
\multicolumn{2}{l}{} & & \\
*ADL: Activities of daily living. & & \\
** Significant difference, Mann-Whitney U, p=0.03. &
\end{tabular}

The means of different groups were compared by MannWhitney U, and Fisher's exact test was used in the analysis of nominal variables.

\section{Results}

Forty-eight of 100 patients had either only synchronous or only alternating activity. Table 1 shows the clinical and neurophysiological characteristics of the patients.

There was no difference between the groups with synchronous and alternating activity in terms of sex, age at onset, duration of illness, family history of tremor, and symmetry and frequency of tremor.

The only significant difference between the groups of patients with synchronous or alternating activity was that the tremorinduced disability of the patients with synchronous activity was higher than that of the patients with alternating activity (MannWhitney $\mathrm{U}, \mathrm{p}=0.03$ ) (Table 1).

\section{Discussion}

Alternating activity of antagonist muscles in a trembling limb is characteristic of Parkinsonian rest tremor, while synchronous muscle activity is associated with ET. ${ }^{3}$

Patients with ET might also have alternating activity of antagonist muscles, and these patients could constitute a subgroup with different clinical, pharmacological, and neurophysiological characteristics. Table 2 shows the characteristics of ET patients with synchronous and alternating activity of antagonist muscles.

The clinical significance of classifying ET according to EMG patterns of antagonistic muscles has been questioned for three reasons:

1) The phasic relationship of antagonist muscles could not always be defined as synchronous or alternating, since there are patterns that reside somewhere between synchronous or alternating activity. ${ }^{2,11}$

2) The presence of either synchronous or alternating patterns has been shown to vary from patient to patient, from task to task, from minute to minute, and could even be different in the right and left hand of the same patient at the same time. ${ }^{2,12}$

3) In a relatively large series (61 patients), neither synchronous nor alternating pattern correlated significantly with other clinical or neurophysiological characteristics of ET. ${ }^{5}$

We designed the present study taking the criticisms mentioned above into consideration. Elble ${ }^{11}$ and Boose et $\mathrm{al}^{2}$ reported intermediate patients who did not show exclusively synchronous or alternating activity, and indeed such intermediate patients constituted $52 \%$ of patients in our study. We evaluated the patients with only synchronous or only alternating activity, thinking that these represented the extremes of the spectrum (if such grouping exists), so any associations would be stronger and easy to detect.

To detect and exclude patients whose contraction pattern changed with time, we used a long recording period $(3 \times 10$ minutes). This is longer than the $3 \times 6$ minute-long period of Elble, ${ }^{11}$ which he said was atypically long. We also recorded from both arms simultaneously and excluded the patients who show different types of contraction patterns in different upper extremities. 
Table 2: The characteristics of reported patients with essential tremor with synchronous and alternating activity of antagonist muscles.

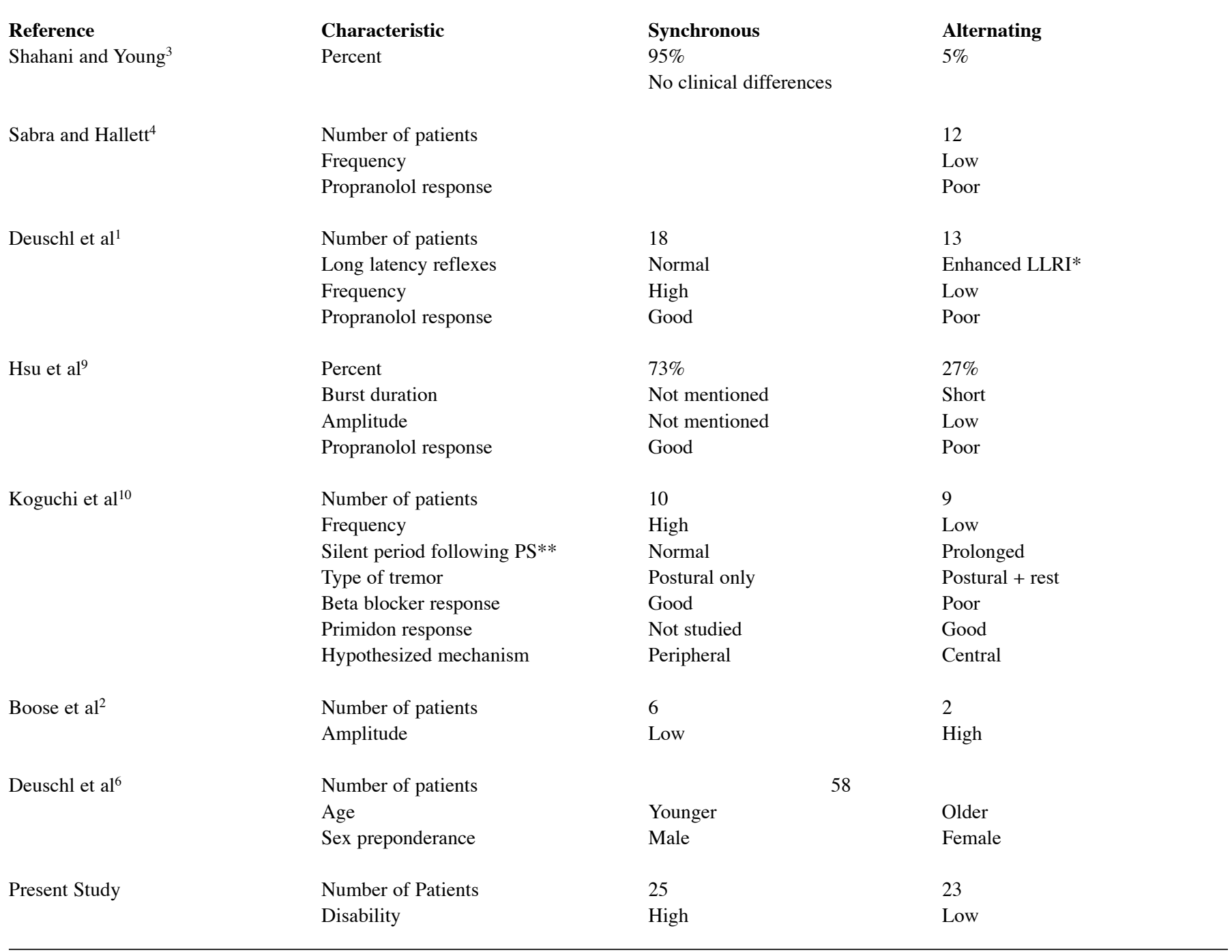

*LLR I: Long latency reflex I.

**PS: Peripheral stimulation

One disadvantage of the present study is the relative lack of objectivity of the visual inspection method (when compared with computerized techniques) that was used to categorize the phasic relations of antagonistic muscle groups; however, the method has been used effectively in similar studies. ${ }^{1,3,4,5}$

The only statistically significant difference between patients with synchronous or alternating activity was that the average activities of daily living score was higher in patients with synchronous activity (Table 1 ). Only Koller et $\mathrm{al}^{5}$ evaluated patients with a functional disability scale. They found no difference in disability between the patients with different phase relationships. This discrepancy with the present results may be due to two methodological differences:

1) We evaluated patients with synchronous and alternating activity of antagonist muscles, and we did not include the patients with flexor-only contractions, while Koller et $\mathrm{al}^{5}$ included patients with flexor-only contractions as a third group.

2) Koller et $\mathrm{al}^{5}$ assessed tremor using three ratings (a selfreporting disability scale, a motor task/function rating, and a scale of tremor severity). They did not mention if they analyzed only the total score or if they also analyzed the disability subscore separately.

It has been shown that voluntary movement in tremulous patients always begins simultaneously with an EMG burst of tremor. $^{13}$ In patients with synchronous activity of the antagonistic muscles, both the agonists and antagonists contract at the same time on the initiation of voluntary movement, without reciprocal inhibition of the antagonist muscle group. This probably makes the performance of the movement more 
difficult and might render the patient disabled. On the other hand, reciprocal inhibition of the antagonist muscles is possible for patients with alternating activity, since the agonists and antagonists do not contract at the same time. Voluntary movement, therefore, takes place more easily than in patients with synchronous contraction of the antagonist muscle groups.

\section{CONCLuSION}

ET patients with synchronous contractions were more disabled than patients with alternating contractions. We think this result contributes to the evidence for distinct electrophysiological subgroups of ET, with distinct clinical properties.

\section{REFERENCES}

1. Deuschl G, Lücking $\mathrm{CH}$, Schenck E. Essential tremor: electrophysiological and pharmacological evidence for a subdivision. J Neurol Neurosurg Psychiatry 1987; 50: 14351441.

2. Boose A, Spieker S, Jentgens C, Dichgans J. Wrist tremor: investigation of agonist-antagonist interaction by means of longterm EMG recording and cross-spectral analysis. Electroencephalogr Clin Neurophysiol 1996; 101: 355-363.

3. Shahani BT, Young RY. Physiological and pharmacological aids in the differential diagnosis of tremor. J Neurol Neurosurg Psychiatry 1976; 39: 772-783.
4. Sabra HF, Hallett M. Action tremor with alternating activity in antagonist muscles. Neurology 1984; 34: 151-156.

5. Koller WC, Busenbark K, Gray C, Hassanein RS, Dubinsky R. Classification of essential tremor. Clin Neuropharmacol 1992; 15: 81-87.

6. Deuschl G, Zimmerman R, Genger H, Lücking CH. Physiological classification of essential tremor. In: Findley LJ, Koller WC, eds. Handbook of Tremor Disorders. New York: Marcel Dekker, Inc, 1995: 195-208.

7. Koller WC, Busenbark K. Essential tremor. In: Watts RL, Koller WC, eds. Movement Disorders: Neurologic Principles and Practice. New York: McGraw-Hill, 1997: 365-385.

8. Bain PG, Findley LJ, Atchinson P et al. Assessing tremor severity. J Neurol Neurosurg Psychiatry 1993: 56: 868-873.

9. Hsu YD, Chang MK, Sung SC, Hsein HH, Deng JC. Essential tremor: clinical, electromyographical and pharmacological studies in 146 Chinese patients. Chung Hua I Hsueh Tsa Chih 1990; 45: 93-99.

10. Koguchi Y, Nakajima M, Kawamura M, Hirayama K. Clinical subtypes of essential tremor and their electrophysiological and pharmacological differences. Rinsho Shinkeigaku 1995; 35: 132136.

11. Elble RJ. Physiologic and essential tremor. Neurology 1986; 36: 225-233.

12. Rothwell JC. Pathophysiology of essential tremor. In: Findley LJ, Koller WC, eds. Handbook of Tremor Disorders. New York: Marcel Dekker, Inc, 1995: 185-194.

13. Elble RJ, Higgins C, Hughes L. Essential tremor entrains rapid voluntary movements. Exp Neurol 1994; 126: 138-143. 